\title{
Injertarse en la Historia. Gesto creativo y estrategias de reapropiación en el activismo global
}

\author{
Ximo Gonzàlez Marí \\ INVESTIGADOR INDEPENDIENTE·Ximglez@hotmail.com
}

Latinoamericanista, licenciado en Filología Hispánica y DEA por la Universitat de València, ha investigado sobre narrativa de mujeres en América Latina y sobre movimientos sociales contemporáneos. Ha publicado diferentes artículos sobre este tema y el libro Stefanía Mosca: contar lo indecible (2012, Caracas: MonteÁvila). Es autor del blog Ardor al arte.

RECIBIDO: 15 DE FEBRERO DE 2013

ACEPTADO: 18 DE MARZO DE 2013

Resumen: Este trabajo trata de desentrañar los modos en que los actuales movimientos sociales impulsan un proceso de reapropiación que se extiende en diversos ámbitos. Ensamblándose a un sistema de comunicación en redes y adoptando nuevas formas de intervención basadas en el modelo de guerrilla artística, estos grupos antagonistas tratan de recuperar para el individuo su rol de sujeto social consciente. A la luz de estas premisas y a partir de algunos casos particulares, señalaremos los radios de acción de estos movimientos centrados en reapropiarse del lenguaje usurpado por la gramática del mercado, recuperar los espacios públicos para el uso colectivo y reinscribirse en el curso de la Historia incidiendo en el orden de lo cotidiano. Reconquistar la propia vida, en definitiva, subvirtiendo el discurso establecido como única verdad.

Palabras Clave: Movimientos sociales, reapropiación, activismo, Historia.

\begin{abstract}
This article explores the new ways current social movements are using to present themselves and initiating a reappropriation process in different social spheres. These social organizations are embracing network communication systems and adopting new intervention forms based on the artistic guerrilla model. By doing so, these antagonist groups try to recover the individual's role as a conscious social agent. This article analyzes how these social movements are conducting a language reappropriation process as a response to the "market grammar". We will also describe the new ways these social movements are trying to recover the public space for a collective use and have an impact on History and the quotidian order. In a nutshell, these movements talk about how to reconquer life by subverting the mainstream discourse that claims itself as the only truth.
\end{abstract}

Key Words: Social movements, reappropriantion, activism, History. 
"Nosotros somos a quienes estábamos esperando" JUNEJORDAN

De forma más intuitiva que rigurosa, los nuevos antagonismos sociales han pivotado sobre un concepto que consideramos clave en sus estrategias: la reapropiación. El capitalismo, diluido en los mecanismos de relación social, ha aislado a los individuos. Fuera de un todo que los contenga, en los márgenes de los grandes discursos políticos que ordenaban el mundo, tratan de ocupar el centro de la escena, el protagonismo expropiado por la verdadera mano invisible. Reapropiarse del lenguaje, reapropiarse de la ciudad, reapropiarse del transcurso de la Historia, reapropiarse de sí mismos, en definitiva. Implícita o explícitamente, numerosas iniciativas aspiran a ostentar un poder que se considera inherente al ciudadano y, por tanto, suplantado. Hablar de reapropiación implica, en estos términos, el reconocimiento simbólico de una toma de posesión totalmente legítima de una soberanía que corresponde por derecho a los invisibilizados y desplazados aunque, en su mayor parte, nunca hayan disfrutado de ella. Los términos reapropiación o recuperación, vienen a señalar, pues, el carácter legítimo de esta reclamación de algo que es propio y que obra en manos ajenas.

Por otra parte, el poder ya es otro. Ejerce su influencia diluyéndose y extendiéndose por todos los ámbitos. Los movimientos contraculturales, de este modo, han visto desplazado su radio de acción a un lugar muy periférico: su adversario directo ya no es el mismo centro del poder, porque el poder ya no tiene un centro: se disemina en todas direcciones. Si se ocupa Wall Street, no es por su capacidad de paralizar el devenir económico: su lucha es otra, va más allá y apunta a lo simbólico. El lenguaje, los signos: el nuevo campo de batalla. Han sido necesarias nuevas estrategias para transmitir el mensaje. Para que su voz llegue a sus destinatarios, esta se ha vuelto más seductiva y menos mediatizada por la línea editorial de los partidos. Debe enraizar en las grietas del poder; debe injertarse en las fisuras del sistema. En cierto modo, su voz ha tenido que independizarse de la voz de su antiguo amo. Lejos ya de la búsqueda de representatividad, los individuos deben asumir el sonido de su propia voz y reinventar el contenido de su mensaje, haciéndolo coincidir con el horizonte de expectativas del nuevo entramado social.

Varios son los obstáculos que ha tenido que afrontar el discurso tradicional de la izquierda para no perder el tren de la Historia, pero tal vez uno de los más inquietantes ha sido la falta de audiencia. Los movimientos que no han caído en el descrédito popular, se han visto impotentes a la hora de difundir sus ideas por su inherente exigencia de rigor teórico. Por otro lado, son muchos los reajustes del sistema a los que debe hacer frente y la mayoría de lo que antes fueron aglutinantes del modelo antagonista, hoy forman parte del sistema que les ha absorbido para reajustarse. Tal es el caso de los sindicatos, cuyo poder 
de convocatoria se ha visto reducido considerablemente. En un mundo postmoderno, donde el poder invade de forma microfísica e indolora las subjetividades, las alternativas deben presentarse de modo diferente a las encorsetadas tácticas y estrategias de la izquierda pre-68.

En las últimas décadas, cuaja un modelo social más flexible, basado más en los engranajes de la sugestión que en los métodos impositivos y medidas coercitivas que los estados desplegaban como única estrategia. Y no sólo se ha diluido eso que antes podía señalarse como poder, sino que este mueve otros resortes contra las voces disidentes. Lipovetsky habla de un modelo seductivo entendido como matriz social: "la seducción se ha convertido en el proceso general que tiende a regular el consumo, las organizaciones, la información, la educación, las costumbres" (Lipovestsky, 2005: 17). También Bauman afirma que la "gran mayoría de las personas -tanto hombres como mujeres- son integrados hoy por medio de la seducción y no de la imposición del orden, de la publicidad y no del adoctrinamiento, necesitan creación y no regulación normativa" (Bauman, 2001: 253).

Cuando la política se reconvierte y adopta las estrategias del marketing empresarial para fidelizar a los ciudadanos, a estos se les reduce al mero papel de consumidores. El ciudadano asume este rol y, a través de procesos microfísicos, lo naturaliza y adopta como propio y único. La relación clientelar se convierte en excluyente y elegir se convierte en la única opción en la brillante era de la mercancía (Lipovetsky, 1990). Es el individuo, abandonado a su propio control, el que toma las riendas de su propia contención social, negándose dócilmente a tocar con su nariz las paredes transparentes de la pecera, tal vez por miedo a encontrarse en medio del océano. Rotos los amarres a grandes discursos que le inscribían en un proyecto (Lyotard, 1998), en una comunidad, en una estrategia común, quedan dispersos, náufragos en una diáspora de individualidades que se entrecruzan sin mirarse a los ojos. Este ser individualizado ha acabado por aceptar que el simulacro es la única realidad accesible (Baudrillard, 2005). La superficie como única verdad. Miles de discursos lo atraviesan, miles de signos atrayentes lo saturan y centran su atención de forma simultánea. Efímeros destellos de información que se solapan y superponen, que se suceden y niegan continuamente, hacen que viva inmerso en esta neurosis permanente.

Señala Antón Fernández de Rota la brecha que se abre el año 68 del pasado siglo en las condiciones de lucha social, en que se generaliza una corriente que se arrastra desde la contracultura de los años 20. Los estudiantes, más cercanos a los intelectuales de izquierdas, dejaban claro que el proletariado, diezmado por los logros de su propia causa, no era el único agente de transformaciones sociales. Si antes habían de darse las condiciones objetivas para que el dogmático proceso revolucionario fuera puesto en marcha, a partir del 68 será la pragmática del deseo la que produzca las condiciones de posibilidad. Se puede si uno quiere, no si el partido lo considera. Se busca transformar las subjetividades, más allá 
de la gestión pública de la política económica de los estados: "su lucha no era tan solo por otra economía sino por cambiar la vida entera" (Fernández de Rota, 2008: 75): las relaciones sociales, las sexuales, la convivencia, el ocio, la educación... En estos nuevos modos de antagonismo post-obrerista, la lucha abandona la fábrica (Hardt y Negri, 2002) y sale a la calle, el lugar de todos, a reclamar su felicidad.

\section{Confluencia de las prácticas activistas}

Vamos a detenernos, antes de abordar los campos de la reapropiación que dividiremos en cuatro bloques, en lo que intuimos como cinco puntos de confluencia en las prácticas activistas que afloran alrededor del mundo. En todos ellos, observamos unos presupuestos que comparten en mayor o menor medida y que derivan de diversos condicionantes que definen el contexto social e histórico en el que inciden.

El primero de ellos es la horizontalidad. El sentido vertical de las antiguas organizaciones se ha vuelto inoperante. En una sociedad individualizada, ningún discurso oficial es capaz de contener la gran diversidad de interpretaciones de la realidad. Comunicados en forma de red, convertidos en nódulos de un entramado que se extiende de forma rápida y flexible, los flujos comunicacionales ya no descienden desde los líderes de los partidos, sino que anegan las redes sociales en toda su inmensidad horizontal. Convergen las individualidades en tanto que sujetos conscientes. Su papel de aplaudidor en los congresos del partido, su rol de votante convencido o manifestante ocasional bajo un lema predefinido, se ve desautorizado y se empieza a reclamar un nuevo sujeto político. En las acciones llevadas a cabo por los movimientos sociales de los que daremos cuenta más abajo, observamos una transposición de roles en el ciudadano, que pasa de espectador a transformador social y productor de reacciones.

El segundo de ellos es el uso de expresiones artísticas como vehículo transmisor del mensaje. Embellecer el discurso es el método de hacer llegar su ideario a sus vecinos. El artivismo, como se viene llamando, es una forma seductiva de emisión. Para dejar de clamar en el desierto, los activistas se han visto obligados a improvisar como artistas y los artistas se han visto obligados a politizar su arte. Efímera es la frontera que los separa y discernirla es una labor ajena a los objetivos del presente trabajo. Nos limitaremos a señalar que en la sociedad de la seducción, solo un lenguaje seductor es capaz de ser escuchado y esta es la lección que han aprendido los que de algún modo intentan sacudir la dormida conciencia social.

El tercero de los elementos es el modelo de guerrilla que adopta el activismo. Sus acciones son rápidas, efímeras, chocantes, subversivas. Su misión es conmocionar y retirarse. Tratan, de forma intuitiva, de asemejarse a los destellos informativos y publicitarios que copan un "orden de comunicación frontal y unilateral" (grupo autónomo 
a.f.r.i.k.a., Blisset y Brünzels, 2000: 14). Aspiran a provocar el shock, el deslumbramiento visual. Lo que se diga reviste poca importancia comparado con la reacción que debe propiciar un lenguaje puramente apelativo que, además, superpone informaciones que serán substituidas por otras de inmediato. Umberto Eco señala la poca validez de los contenidos de los medios en una sociedad massmediatizada, para él la naturaleza de la información tiene menos importancia que el bombardeo gradual y uniforme de la información. Pero, lejos de pensar que quien tiene los medios tiene el poder, Eco afirma que el poder reside en el hecho de la recepción y decodificación del mensaje:

Habrá que aplicar en el futuro a la estrategia una solución de guerrilla. (...) en el momento en que los sistemas de comunicación prevén una sola fuente industrializada y un solo mensaje, (...), nosotros deberemos ser capaces de imaginar unos sistemas de comunicación complementarios que nos permitan llegar a cada grupo humano en particular (Eco, 1999: 143).

Yendo más allá, podemos afirmar que la sociedad de redes y el activismo postmedios convierten al espectador en creador de información y transmisor de la misma. Parece que el antiguo esquema emisor-receptor ha solapado su antigua polarización. De hecho, las acciones de los movimientos activistas a los que nos referiremos representan verdaderas estrategias de guerrilla comunicacional ajenos a los flujos informativos de los massmedia. Sonja Brünzels, junto con el grupo autónomo a.f.r.i.k.a. y el nombre colectivo Luther Blisset, firman el Manual de Guerrilla de Comunicación. En él se señala que

la metáfora de la guerrilla resulta ciertamente apropiada (...), ya que la guerrilla no opera desde una posición visible como un ejército oficial, sino desde las sendas accidentadas y perdidas, alejadas de las grandes rutas. La guerrilla no necesita de muchas personas, aunque sí que depende de la complicidad o, por lo menos, de la tolerancia de la población. Su táctica se basa en el conocimiento del terreno. Actúa de manera local y en momentos puntuales" (grupo autónomo a.fr.i.k.a., Blisset y Brünzels, 2000: 9).

Son intervenciones breves, espontáneas, efímeras. La guerrilla de la comunicación es "una forma defensiva de práctica política, y hoy en día se deciden por ella pequeñas agrupaciones temporales que no pueden movilizar una base masiva y que, por lo tanto, no tienen más remedio que desarrollar formas visibles de intervención pública con un esfuerzo mínimo" (grupo autónomo a.fr.i.k.a., Blisset y Brünzels, 2000: 222). La optimización de recursos, el anonimato, el efecto sorpresa, son las garantías de éxito para este tipo de agrupaciones nodulares y rizomáticas que aparecen por sorpresa y se desvanecen.

Como cuarto elemento común, cabe detenernos en el carácter humorístico de muchas de las intervenciones activistas. La carcajada es la reacción más eficaz. La política, de hecho, ha suavizado su discurso, ha edulcorado sus consignas, ha demonizado el 
pensamiento doctrinario. La clase política ha entendido que, para llegar a sus fieles, hay que establecer el modelo del Club de la Comedia y favorecer la McDonalización de los programas. El humor es otra máscara, otro recubrimiento, una frontera que nos distancia de lo otro. El extrañamiento es el punto de vista que adopta sujeto que se ve obligado, en cierto modo, a interactuar con lo señalado: reírse de algo significa establecer una posición respecto a lo risible. Es por esa toma de conciencia colectiva que la ironía ha sido rápidamente adoptada por los movimientos sociales como modelo discursivo de sus acciones. En sus intervenciones, se reapropian del discurso oficial de su adversario, lo cuestionan como construcción social naturalizada, lo desenmascaran y lo transforman en su opuesto para que diga lo que debiera decir. Esta subversión de los códigos lingüísticos sobre los que se asienta el modelo de simulacro social es la verdadera rebelión, la oxidación de sus engranajes. Con ese chirrido, la sátira devuelve al poder constituido la realidad de su propia imagen. Por ello, se cuestionan los discursos cerrados y autosuficientes para crear situaciones abiertas y ambivalentes.

En otras palabras, se recurre al humor, a la parodia, a la sátira, al juego de palabras, etc., porque sólo con contar la verdad no vale: también hay que hacer que alguien la escuche. La revolución será divertida, o no será. Esta parece ser una de las máximas de las nuevas formas de activismo social que nos ocupan. En definitiva:

Renovar la práctica política de izquierdas con una buena dosis de guasa (...) La diferencia con otras posturas militantes (...) radica en que no se apunta a destruir los códigos y signos del poder y del control, sino a distorsionar y desfigurar sus significados como modo de contrarrestar su todopoderosa alucinación de poder. (...) Los activistas acercan la lucha al campo de la cultura Pop, constituyen simulacros inteligentes, difunden noticias falsas utilizando la ironía para retirarse en el momento preciso. El "giro pop" significa que los activistas se han vuelto menos aburridos y hablan el lenguaje de las masas" (Franco Monthiel, 2003).

Pero no sólo se trata de convertir las reivindicaciones en acciones de carácter más o menos lúdicas. Como quinta y última observación antes de adentrarnos en los bloques que componen este artículo, diremos que se explicita en la mayoría de acciones del activismo una inclinación a acotar lo cotidiano como esa esfera a la que no debe renunciar la política. Se da por hecho, abandonando el economicismo como motor revolucionario, que la búsqueda de la felicidad personal ha de ser el objetivo de toda revuelta, es decir, la politización de la vida privada. “ $¡$ Ninguna revolución sin juerga, ni juerga sin revolución!” (grupo autónomo a.f.r.i.k.a., Blisset y Brünzels, 2000: 222). Pero esta consigna debe ser matizada: no se quiere significar que la diversión por sí sola represente una subversión de carácter político o social. Con esta afirmación sólo se quiere hacer patente que las 
intervenciones de los diferentes grupos apuntan a rescatar al sujeto como persona integral, como humano y no sólo como consumidor o productor.

Estos van a ser los cinco anclajes sobre los que este trabajo se asienta para tratar de arrojar luz sobre los modos de reapropiación en las intervenciones del activismo globalizado. En lo que sigue, haremos un recorrido por diferentes prácticas de intervención social que emergen en todo el mundo y que comparten la caracterización que acabamos de esbozar. Las agruparemos en cuatro apartados que señalan el campo de acción sobre el que inciden estos movimientos. Primeramente, abordaremos el lenguaje como engranaje que construye el universo cultural mediatizado por el discurso publicitario y que movimientos como Yomango usan en su favor. Seguidamente, atenderemos a la transformación del espacio urbano convertido en canales de tránsito o de consumo para rescatar su valor público y su carácter artístico y estimulante, como es el caso de la Guerrilla del ganchillo o el Parking Day. Más tarde, nos detendremos en la reapropiación de la Historia, es decir, aquellos movimientos como el $15-M$ derivados de la movilización social y que tratan de acceder a un nuevo rol protagónico que intuyen inherente a su condición de ciudadano. Por último, incluiremos en otro apartado algunas de las iniciativas que aspiran a la propia visibilización de los excluidos y a la valorización de su dignidad, como es el caso de las bolivianas Mujeres Creando.

\section{Recuperar el lenguaje}

Yomango no es un colectivo, no es un movimiento social. Se define como una corporación, una empresa más. Es más, es una empresa que ha extendido sus redes a diversos continentes: es una multinacional. De hecho, afirman tener franquicias repartidas por el mundo, coordinadas por su Departamento de Marketing. Sin embargo no venden nada. No producen nada. Y esa es, justamente, la razón por la que pueden hablar de sí mismos como de una marca. Según Leónidas Martín, uno de sus miembros, "Yomango no vende nada, es sólo un estilo de vida: el estilo de vida Yomango" ${ }^{1}$ y este no es otro que la defensa del libre intercambio de bienes y deseos. Esta afirmación coincide con lo aportado por Naomi Klein al respecto, cuando señala la preferencia de las grandes multinacionales por lo inmaterial, lo que no tiene stock ni volumen de almacenaje: se venden valores, estilos de vida (Klein, 2001). Coca Cola vende felicidad, Nike vende la capacidad de conseguir lo que te propones.

Reciclando el logo de la marca de ropa Mango, Yomango se construye como una imagen corporativa que arenga a los individuos a robar artísticamente en los supermercados. Incluso explican sencillos y divertidos métodos de hurto menor en su

1 Declaraciones extraídas del documental "Arte y activismo", emitido en el espacio televisivo Metrópolis (Rtve) el día 28 de febrero de 2010. 
Libro Rojo de Yomango ${ }^{2}$. Uno de ellos es hacer saltar, de forma colectiva, las alarmas en todas las cajas de un hipermercado para provocar la confusión de los agentes de seguridad y poder así celebrar una fiesta improvisada en el mismo aparcamiento con los jamones y el champán socializados durante la algarabía. El hecho mismo de convertir el hurto en performance, en un verdadero evento social, no dista demasiado de lo acontecido hace unos meses en Sevilla cuando el diputado Juan Manuel Sánchez Gordillo, entre otros activistas, se llevaron sin pagar varios carros llenos de productos de primera necesidad. Con ello pretendían señalar los altos niveles de pobreza que azotan a los más desfavorecidos por la crisis. En la recurrencia a este tipo de intervenciones observamos su potencial éxito.

Yomango adopta el discurso imperante, el lenguaje empresarial que nos define como productores y/o consumidores. Fuera de esta dicotomía, no hay comunicación posible. Eso es lo que parecen decir, apropiándose de la gramática mercantil para dar forma a su imagen de marca. Hablan con los códigos de su adversario, parodian su lógica, evidencia su naturalización como parte de nuestros discursos cotidianos. De hecho, hacen suyos algunos eslóganes publicitarios de compañías como Visa ("Lo quieres, lo tienes") o Mastercard ("Hay cosas que el dinero no puede comprar. Para todo lo demás, Yomango"). Comenta Leónidas Martín que "Yomango es en sí mismo una reapropiación. El propio nombre lo es y todo lo que realizó fue, de alguna manera, mangado"3. Ese lenguaje unívoco, unilateral, que condiciona al sujeto y lo reduce a un mero plano mercantil, cobra otros sentidos en las intervenciones de Yomango. Es el lenguaje del mercado desenmascarándose a sí mismo, tensándose hasta el extremo, explicitando la verdad que esconde.

Tal subversión se crea a partir de un proceso de sobreidentificación: no se trata simplemente de ironizar, de parodiar, de distanciarse de aquello que se quiere señalar. Lo que se pretende es otra vuelta de tuerca: ser extremistas en este discurso, acogerlo de forma más doctrinaria que sus emisores originales. Blisset y Brünzels aportan al respecto el ejemplo del colectivo de artistas esloveno Neue Slowenische Kunst (NSK), surgido en la década de los 80. En las actuaciones de su banda de rock, Laibach, adoptan abiertamente la imaginería y estética fascistas; la extreman, la hacen verosímil eliminando cualquier mecanismo de distanciamiento, cualquier guiño irónico, cualquier elemento satírico. Debe parecer real para que, de forma casi aristotélica, se produzca una suerte de catarsis en el espectador.

Aunque los activistas de Yomango no llevan a tal extremo su discurso, sí tratan de hacerlo coincidir con el que adoptaría cualquier corporación, reapropiarse del lenguaje, insertarse en los discursos ordenadores del mundo y hacerlos hablar con otras voces;

\footnotetext{
2 Manual que se vale de la estética Maoísta de la Revolución Cultural y parodia el Libro Rojo de Mao: http://www.sindominio.net/fiambrera/007/ymng/librorojo/librorojo.htm

${ }^{3}$ Vid nota 1.
} 
subvertir los códigos, deconstruirlos y hablar con los restos semiológicos de los lenguajes con los que se enuncia el poder. Se han posicionado dentro de "la lógica del orden dominante y atacarla en su punto más vulnerable, o sea, en su centro; (...) expresar de modo afirmativo dichos aspectos callados y hacerlo de forma convincente, imitando la lógica del sistema con la máxima fidelidad" (grupo autónomo a.f.r.ik.a., Blisset y Brünzels, 2000: 55). El discurso constituido responde a

un sistema de ordenación cuyo poder se basa en gran medida en ser aceptado como algo incuestionable. Se trata, pues, de alterar el orden pacífico de los signos para poder llamar la atención sobre este sistema de orden y sus funciones estabilizadoras. Eso significa, en el mejor de los casos, adueñarse de sus espacios vacíos, decir lo no dicho y desvelar al mismo tiempo cómo actúan de manera oculta los vacíos y los silencios en el lenguaje. Tal tergiversación y cambio de sentido agrede los fundamentos simbólicos del orden social (grupo autónomo a.f.r.i.k.a., Blisset y Brünzels, 2000: 89).
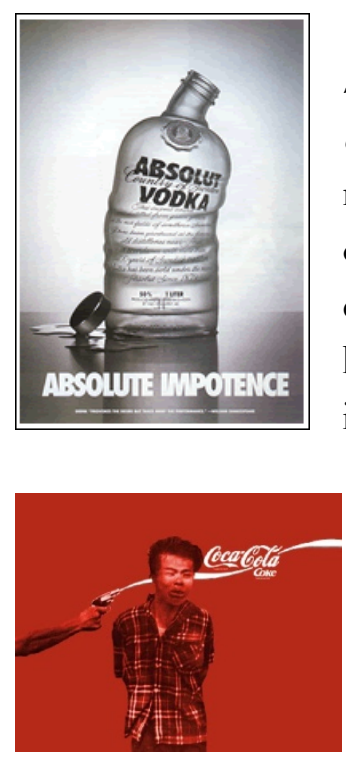

Un mecanismo contrario al de sobreidentificación es el principio de distanciamiento, al que ya hemos hecho referencia. Provocando extrañamiento y confusión mediante la alteración de los signos esperados, se produce esa reflexión posterior que buscan, por ejemplo, los piratas publicitarios. Su misión es la de incorporar un elemento desestabilizador del significado a un mensaje que normalmente sería percibido dentro del orden normal de las cosas. "La gramática cultural forma parte de una mitología de la cotidianidad donde el poder y el dominio se presentan como hechos naturales" (grupo autónomo a.f.r.i.k.a., Blisset y Brünzels, 2000:

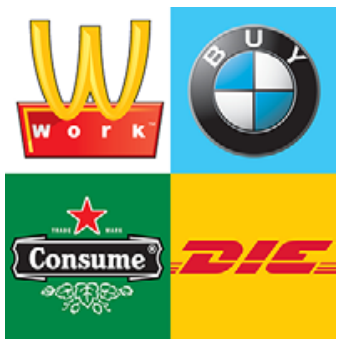
21) y cualquier cambio en su representación usual provoca confusión y extrañamiento en el receptor, lo que abre nuevas vías de significación.

Todo ese andamiaje cultural sobre el que se asientan los presupuestos que permiten la comunicación se viene abajo cuando aparecen elementos distorsionadores y es justo entonces cuando vemos la verdadera imagen de lo real. Comenta al respecto Naomi Klein que los rompeanuncios no alteran los mensajes, sino que los desenmascaran. "La piratería publicitaria correcta es una visión de rayos $\mathrm{X}$ del subconsciente de la campaña publicitaria 


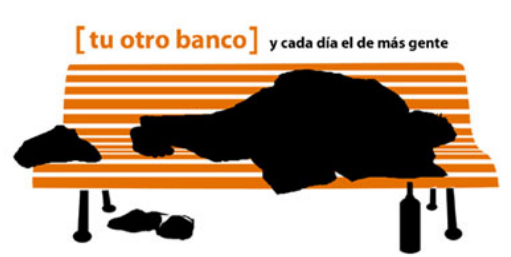

que no revela un pensamiento opuesto a ella, sino la verdad profunda que se esconde tras las capas de eufemismos publicitarios" (Klein, 2001: 332).

Romper esta normalidad que nos reconforta como espectadores es su misión.

Este método de reapropiación con fines políticos hoy cuenta con muchos adeptos, aunque tiene un claro precedente en los situacionistas franceses, para quienes el détournement o descontextualización de imágenes, códigos o textos de su marco original abría un nuevo abanico de significados en los mensajes originales. Un claro ejemplo de esto son las calaveradas que inició Jubal Brown en Toronto el día de los Inocentes de 1997 (Klein, 2001: 337). Decenas de personas se dedicaron a retocar los rostros de las modelos que son exhibidas en las vallas publicitarias. Ennegrecieron sus ojeras, demacraron sus facciones, añadieron cremalleras a sus bocas para asemejarlas a calaveras. Con esta acción se denunciaba la mercantilización del cuerpo femenino expuesto como simple cebo publicitario. El objetivo es evidenciar el verdadero carácter de las empresas que se anuncian, un ataque directo a su imagen de marca, al estilo de vida que venden o a la cruel verdad que esconde su retórica del mercado.

En conclusión, podemos intuir detrás de las aspiraciones de estas prácticas antagonistas una querencia a decir entre líneas. Se valen de diferentes mecanismos para reapropiarse del lenguaje y mostrar lo que calla, hacer valer las diversas voces dialógicas obviadas por el monólogo economicista del consumo. En esta práctica que podemos definir como reciclaje lingüístico se explicita, pues, esta demanda por la reapropiación de los canales comunicativos monopolizados hasta ahora por el monólogo del mercado.

\section{Recuperar el espacio}

Intervenidos por la lógica del dinero, las ciudades también se han visto sometidas, limitadas o coartadas por los intereses del mercado. Las calles ya no son lugares de disfrute o permanencia, sino espacios dedicados al tránsito de personas y coches, canales de distribución de seres humanos y máquinas. Las fiestas oficiales representan estados de excepción en el orden del calendario. Sólo entonces está permitido hacer un uso lúdico de los espacios públicos. Contra esta usurpación de la calle reaccionan ciertos movimientos sociales cuyo objetivo es reivindicar el aspecto comunitario de vías y plazas.

Merece la pena detenernos para considerar el nuevo estatuto de las ciudades. La ciudad post-panóptica, el espacio postmoderno, "no es un lugar, sino un tener lugar de los cuerpos que lo ocupan" (Delgado, 2007: 13); no es un contexto, sino una maraña de redes relacionales que configura el devenir urbano, desintegrándose y rehaciéndose constantemente, construyéndonos y desintegrándonos como parte de esa realidad en eterna 
reformulación. Debemos, pues, entender que el activista urbano tiene por obligación que desenvolverse en esta ciudad líquida en eterna reconstrucción, surfear en su superficie, bucear en sus profundidades. Pero sobre todo, atenerse al carácter cambiante y efímero tanto del paisaje urbano como de la ciudad en sí misma.

Por una parte, encontramos a aquellos que pretenden embellecer el espacio urbano. Del mismo modo que la Psicogeografía de los situacionistas franceses buscaba una experiencia artística en el mero hecho de vagar y enfrentare a lo inesperado y azaroso del paseo, estos activistas optan por la museificación de las calles como acto subversivo en sí mismo. Sacar el arte de las galerías y acercarlo a las personas. Lo cotidiano como campo de batalla, recuperar el paisaje urbano más allá de la publicidad que no elegimos ver cada mañana y que representa una invasión visual que ha acabado por no molestar al ciudadano; ese algo que ya estaba ahí cuando llegamos, como un árbol o un río. Sirvan como muestra las intervenciones anónimas de la guerrilla del ganchillo (guerrilla knitting o yarn bombing), que aspiran a dar color y una textura amable al mobiliario urbano. El trayecto hacia otro punto de la ciudad se vuelve un acto lúdico, artístico. Reivindican la ciudad como espacio de goce visual, disputándole las miradas a los anuncios o los escaparates. La ciudadmercancía se transforma en un eventual museo para el viandante, que interactúa de otros modos con el asfalto y los muros que lo contienen.

Con la misma intención estética se mueve Acción Poética, un grupo muralista nacido en Argentina y extendido a todo el continente. Su práctica es pintar murales con versos de poetas latinoamericanos en los muros, poetizando de este modo la trama urbana. Se vuelven reconocibles porque son fieles a una estética común: letra mayúscula en negro sobre fondo blanco, imitando la escritura en papel. Se vislumbra con este acto que la ciudad es un texto que puede ser reescrito, un verso que está por leer y se recita a sí mismo al volver la esquina.

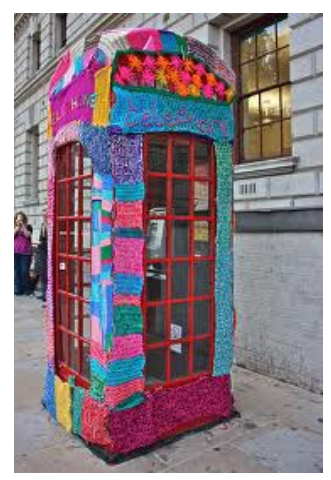

Otra propuesta no menos interesante es $\operatorname{Park}(i n g)$ Day ${ }^{4}$. El pasado 21 de septiembre de 2012 fue la última convocatoria para convertir, en diferentes ciudades del mundo, plazas de parking en improvisados parques e incluso playas. Se trata de pagar unas horas de aparcamiento en el centro de la ciudad y disfrutarlo como espacio de ocio. En definitiva, recuperar la ciudad como un lugar de convivencia e intersección de individualidades; crear un verdadero campo de excepción al imperio de los coches, un margen interior al "metro-

\footnotetext{
${ }^{4}$ La primera intervención fue llevada a cabo por el grupo de diseñadores Rebar, el 5 de noviembre de 2005, en San Francisco:

http://parkingday.org/wp-content/uploads/2010/07/ParkingDay2012 Rebar press release.pdf
} 
boulot-dodo" ${ }^{5}$ que define la ciudad como un mero canal de tránsito. El mensaje parece claro: el espacio público es de todos, allí donde los ciudadanos encuentran un potencial espacio común de resistencia ante la infelicidad y el desarraigo social. La calle es, en esencia, el lugar donde resistir.

En la misma línea se mueven Desayuno con viandantes. Un grupo de arquitectos y artistas de Valencia, siguiendo anteriores precedentes en otras ciudades, coordina un desayuno, un sábado al mes, compartido en un espacio público de la ciudad. Pero no sólo ocupan espacios públicos, también aquellos que, en su opinión, debieran tener la misma consideración. El objetivo es privilegiar la cultura de lo exterior, reapropiarse de los espacios que son de todos. En este proceso de individualización que sufre la sociedad merced a su mercantilización y al control social procurado por el miedo como lubricante microfísico, el sujeto se encierra en su casa, en su coche, en su urbanización. Levanta un muro entre sí mismo y el afuera. El interior es el garante de cierta seguridad, de cierta previsibilidad frente a lo que acecha del lado de allá de la piel. Con este tipo de intervenciones, se encarna el "elogio de la experiencia exterior, esto es, de la vida fuera de la vivienda, a la intemperie de un espacio urbano convertido en una dinamo de sensaciones y experiencias" (Delgado, 2007: 28). Fuera, el individuo obtiene

Ventaja de aquellas mismas cualidades que podrían haberse percibido inicialmente como fuentes de desazón: la incertidumbre, la ambivalencia, la extrañeza. En el exterior se extiende en todas direcciones el imperio infinito de las escapatorias y las deserciones, de los encuentros casuales y de las posibilidades de emancipación. Si el dentro es el espacio de la estructura, el afuera lo es del acontecimiento (Delgado, 2007: 28-29).

Hacer de un acto privado un evento público plantea una subversión de los códigos interiorizados por los individuos, la llamada gramática cultural, abriendo un significado reivindicativo para un gesto cotidiano reconvertido en un punto de encuentro festivo:

El desayuno participativo no es una protesta, sino una celebración de la calle, identifica festivamente las posibilidades de uso del espacio público y es, por tanto, una representación urbana de algo cotidiano, y causa contraste con la rutina de la ciudad. Son una manera atractiva de activar la calle a partir de los rituales domésticos, de encontrarse con una red de ciudadanos conscientes y preocupados por lo público (Desayuno con viandantes, 2012: 4).

Abundando en la vertiente lúdica de las intervenciones urbanas, podríamos referirnos a las numerosas ocupaciones de oficinas del INEM y entidades bancarias por

\footnotetext{
${ }^{5}$ Metro-trabajo-dormir. Se trata de una expresión derivada de un verso de Pierre Béarn: "Au déboulé garçon pointe ton numéro / Pour gagner ainsi le salaire / D'un morne jour utilitaire / Métro, boulot, bistro, mégots, dodo, zéro".
} 
parte de personas anónimas que se citan para celebrar una fiesta o escenificar un flashmob. Incluso Yomango participó en una fiesta improvisada en el Metro de Londres en protesta por los precios abusivos del transporte público. Ocupar los espacios sagrados del capitalismo (el banco, la oficina de empleo, etc.) es un gesto de reapropiación del poder cedido, señalar la farsa del contrato social, recuperar los escenarios donde se representa la hegemonía y, además, celebrarlo como acto de subversión.

Podemos nombrar otras iniciativas que tratan de convertir la calle en un espacio artístico, concretamente, musical. Rhythms of Resistance nace en el año 2000 en la ciudad de Londres. Parten de los instrumentos y ritmos de la percusión brasileña de samba y los convierten en una forma de resistencia frente a la represión policial en manifestaciones y actos reivindicativos, creando una barrera rítmica entre los manifestantes y las fuerzas represivas. Se diseminan por diversas ciudades europeas y funcionan de modo horizontal, compartiendo los ritmos de forma que puedan unir sus tambores en grandes encuentros o manifestaciones altermundistas. Otro grupo similar fue The Infernal Noise Brigade, nacido en Seattle durante las protestas contra la cumbre de la OMC. Algo curioso de esta banda es la adopción de la iconografía dictatorial. Sus intervenciones eran auténticas marchas militarizadas, donde se hacían malabares con rifles, se agitaban banderas y se caminaba de forma marcial. Este proceso de sobreidentificación crea, en un primer momento, confusión entre los agentes antidisturbios. Pero una lectura simbólica de su discurso acaba por desenmascarar y caracterizar el sistema neoliberal que se defiende en el interior de la cumbre. En el exterior, marchando y tratando de ocupar ese centro irradiador de poder, desde la calle, desde los márgenes del sistema, se escuchan ritmos de resistencia.

Debemos incluir, desde otra perspectiva, otras reapropiaciones del espacio urbano que también presentan interés. Se trata de numerosos intentos de reconvertir los espacios vacíos que abundan en las diferentes geografías urbanas en huertos de producción de

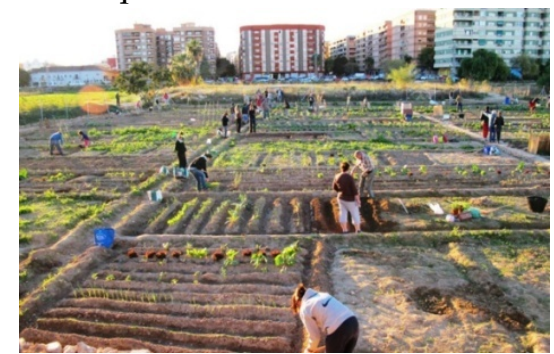
verdura ${ }^{6}$. Decenas de solares llenos de basura son limpiados anónimamente para su uso agrícola en numerosas ciudades. Más allá de hacer productivo un pedazo de la ciudad y transformarlo en un pequeño espacio verde, debemos centrar nuestra mirada en el hecho metafórico de esta ocupación, a ese significado ulterior que se abre.

Ese distanciamiento es una grieta en nuestra gramática cultural. Eso que chirría y llama nuestra atención remite a la idea de decrecimiento, una opción alternativa al desarrollo capitalista que defienden muchos movimientos sociales en la actualidad. Contra el crecimiento infinito y acelerado de la economía, que marca la línea de actuación del

${ }^{6}$ http://www.huertosurbanosbenimaclet.com/ 
neoliberalismo, Carlos Taibo afirma con rotundidad que el decrecimiento supondría mejoras sustanciales en la redistribución de los recursos, la preservación del medio ambiente, el bienestar de las generaciones futuras, la salud de los ciudadanos o las condiciones del trabajo asalariado:

El problema principal del concepto de desarrollo que manejamos es que se halla claramente impregnado, en los hechos, de todos los rasgos propios del crecimiento. El desarrollo realmente existente, por decirlo de otra manera, aspira a transformar en mercancía las relaciones entre los seres humanos y las que estos mantienen con la naturaleza (Taibo, 2009: 47).

Estas iniciativas, con su mera realización, no hacen más que señalar que esa forma de vida que no atente contra nosotros mismos es posible todavía y que, si se rasca fuerte, bajo el asfalto hay un huerto dispuesto a florecer.

Los diferentes movimientos sociales a los que nos hemos referido en este segundo apartado dan fe de un nuevo modelo espacial. En definitiva, tratan de reapropiarse de la calle, recuperar el espacio público que por definición es el espacio de todos y que potencialmente representa el legítimo lugar de la política y de la transformación social.

\section{Recuperar la historia}

No podemos obviar, llegados a este punto, dos prácticas ocupacionales que revisten una importancia crucial. Nos referimos a las acampadas en diferentes ciudades españolas subsiguientes a la salida a la calle de aquellos individuos que conformaron el Movimiento 15-M, después llamados Indignados, y al movimiento Ocuppy Wall Street. En mayo de 2011, una multitud sale a la calle convocada, 13 días antes, por un foro en Facebook, bajo el lema ;Democracia real YA! En dicho foro, debatían personas heterogéneas, pertenecientes a diversos colectivos congregados a causa de su preocupación ante la crisis financiera. El éxito fue rotundo: decenas de miles de manifestantes abarrotaron las calles de las ciudades más pobladas. Sorprende el seguimiento masivo de la convocatoria, más si tenemos en cuenta que los medios de comunicación la obviaron por completo. De hecho, la información que iban ofreciendo tras las movilizaciones eran extractos de los contenidos que circulaban por las redes sociales. Esto demuestra, en palabras de Javier Toret, uno de los iniciadores de „Democracia real YA., que

Es un tipo de movimiento postmedios. Es postmedios porque hay una reapropiación tecnopolítica de las herramientas, tecnologías y medios de participación y comunicación actuales. Ahí es donde está la gente hoy. Hay mucha gente en estos medios. Es una campaña viral online que está lo suficientemente abierta para que cualquiera pueda participar. Para que algo sea viral online, para que sea mimético, los eslóganes tienen que hacerse eco. Por 
ejemplo "No somos mercancía en manos de banqueros". (...) Esto hizo que cada uno fuera su propio medio de comunicación. (...) Nos convertimos en un colectivo que tenía la capacidad de hablar por sí mismo sin los filtros de los medios (Castells, 2012: 124-125).

Esta reapropiación del proceso comunicativo convierte a cada ciudadano en un agente de cambio, integrante de esta narración colectiva que se construye desde diferentes puntos de vista, a veces in situ. Sin líderes, cada cual establece un vínculo horizontal con otros nódulos de comunicación con los que interactúa. El movimiento nunca ha seguido unas directrices marcadas desde arriba, desde ningún partido ni sindicato, es el ciudadano ocupándose de la gestión política, retomando sus funciones, reapropiándose de la política. ¡Democracia real YA!' es un conjunto de individualidades, lo que entronca con el concepto de multitud aportado por Antonio Negri y Michael Hardt: una "pluralidad de subjetividades (...) en continuo movimiento [que] forman constelaciones de singularidades y acontecimientos que imponen al sistema continuas reconfiguraciones globales, (...) dentro del imperio y contra el imperio" (Hardt y Negri, 2002: 71) ${ }^{7}$.

No se sustenta sobre una estructura preestablecida, no es una agrupación que responda ante nadie. Es un rehacerse y reformularse continuamente a través de una enorme red de individuos interconectados. Es un todo inclusivo, una reunión de singularidades bajo un logo que visibiliza a gente sin rostro: "La campaña era anónima. ;Democracia real $Y A$ ! no era nada. Era un conglomerado de blogs, de distintos grupos, gente que venía de grupos contra la Ley Sinde o No Les Votes. ¡Democracia real YA!'era una marca detrás de la cual no había nadie" (Castells, 2012: 116). La multitud surge de la convergencia de diferentes preocupaciones personales: parados, desahuciados, personas dependientes, estudiantes, trabajadores precarios, pensionistas y, en general, ciudadanos que han visto cómo empeoran sus condiciones de vida.

Desde lo personal de sus problemáticas cotidianas, surge una fuerza colectiva que no desemboca en un Uno, no presenta un programa unívoco, no predica una solución para salvar al mundo a través de una Utopía redentora. Antón Fernández de Rota observa que, tras romper con la idea dialéctica de la revolución, "todas esas singularidades, desde la cesura simbolizada por el 68 , ya no podrán aspirar a nada más que una federación transversal; una articulación de las distintas singularidades antagonistas sin primacía de una de ellas ni subordinación de las restantes" (Fernández de Rota, 2008: 76). En efecto, en tanto que singularidades, la naturaleza de la multitud es huir de la usurpación de su discurso en pro de otro que lo ha fagocitado; lo que no significa que no se articulen en

\footnotetext{
7 El término multitud, muy recurrente en Negri y Hardt, ha sido también ampliamente desarrollado por otros autores como Paolo Virno (2003). Rescata el término de Spinoza como una pluralidad que no converge en un Uno, que no se diluye en un movimiento centrípeto.
} 
forma de red conformando una forma liberada del poder constituyente que se avanza y se opone al poder constituido.

El antagonismo actual, la multitud de carácter post-soviético, se opone a la masa en tanto que esta diluía sus singularidades en un todo programático y vislumbraba un futuro de salvación hacia el que se caminaba como único destino posible. Por el contrario, la multitud es anti-dialéctica: favorece el acontecer de pequeñas revoluciones en el seno de lo cotidiano de forma esporádica. La revolución, como la Historia, no ha muerto: "lo que ha entrado en crisis es la noción militar-utópica de la revolución" (Fernández de Rota 2008a: 84). Ya no se lucha por grandes palabras, se lucha por las palabras del día a día. El viejo militante de carnet tiene los días contados:

Ya no podrá construirse un "sujeto político" en los términos de la vieja identidad, que en definitiva remitía a un símbolo central (la clase, el proletariado) y a una práctica de poder que estaba en posición de explicar el resto (la explotación). En lo sucesivo, el Movimiento tendrá que vérselas con una multiplicidad de poderes que son combatidos y con una multitud de deseos e identidades irreducibles a la unidad. La multitud es siempre diversa y plural. Una multiplicidad de fugas subjetivas y contra-poderes que, al aceptarse la consigna "lo personal es político" lanzada por el movimiento feminista, ya no podrá ubicar a sus rivales políticos solamente en las grandes instituciones (Estado, escuela, etc.). El poder no desciende de ellas, sino que se produce en todas direcciones. Hay que disiparlo de los cuerpos, de la producción política de la corporalidad, en los intersticios de poder/saber de los que emerge el self, un estado más íntimo que nuestra propia conciencia. (Fernández de Rota, 2008a: 77).

Después de la masiva manifestación del 15-M, llegaron las acampadas. Es significativo que la idea de ocupar la Plaza del Sol en Madrid cuaja en la intención de debatir acerca del significado de una democracia real. A día de hoy, poco importa la productividad de dicho debate puntual -al que siguieron las numerosas asambleas populares que regularmente se celebraban en las plazas y la espontánea creación de diferentes comisiones de trabajo-; lo relevante es que esta ocupación simbólica de la práctica política significa la reapropiación de un poder usurpado. Cristaliza aquí la crisis de legitimidad que afecta tanto al sistema democrático como a la clase política. Esa reconquista del espacio público inicia la ocupación simbólica del antes abandonado campo político y social. Lejos de perpetuar la predicción de Fukuyama (1992) anunciando el fin de la Historia -presuntamente detenida en ese estado ideal donde el progreso es un fin en sí mismo, el eterno retorno del capital retro-alimentándose-, los individuos retan al futuro y salen a la calle a restablecer el curso del verdadero progreso humano. Aceptan un papel 
protagonista en el devenir histórico, en la "transformación de la pseudodemocracia en democracia real" (Castells, 2012: 127).

Queda patente la necesidad de reformar el sistema en su integridad y se traza así una línea de no retorno. Cualquier programa político que pudiera ser presentado a las elecciones queda desautorizado: "No se trataba de crear un programa que hubiera que aprobar en la siguiente elección (...). El movimiento tenía que recorrer un largo de camino desde la negación del sistema hasta la reconstrucción de las instituciones" (Castells, 2012: 129). La verdadera conclusión es la toma de conciencia colectiva como individuos políticos de que todo está por hacer y la Historia está por escribirse.

Es curioso que, a pesar de la increíble internacionalización de las protestas y acampadas a alrededor de 800 ciudades del mundo en pocos días, fue poca la repercusión de los Indignados tuvieron en Estados Unidos. Tendría que llegar el 17 de septiembre del mismo año para que los activistas norteamericanos se decidieran a ocupar Wall Street. A pesar de ser expulsados de sus campamentos por la policía, estas ocupaciones tuvieran gran impacto en la conciencia del país, de tal modo que la revista Time declaró al manifestante "hombre del año".

Tal vez uno de los aspectos más reseñables es la negación de cualquier representatividad. En una en una intervención pública para los integrantes de Occupy Boston, Noam Chomsky advierte: "Vosotros no queréis líderes; queréis hacerlo por vosotros mismos" (Chomsky, 2012: 48). Advertimos la misma horizontalidad en las decisiones y organización del movimiento ocupacionista en Estados Unidos que en los Indignados. Siguiendo un proceso paralelo, las convocatorias fluyen en las redes y llegan a todos los rincones. El movimiento Ocuppy es un centro de convergencia de inquietudes diversas, una confluencia de individuos personalmente indignados con las instituciones financieras que se erigen como verdaderos centros del poder económico globalizado.

También ellos toman conciencia de la necesidad de hacerse visibles y de recuperar su papel en la Historia. "La forma de narrar puede ser cambiada desde abajo hacia arriba y alterar la narración es una victoria necesaria en el camino hacia la transformación de todo lo demás" (Chomsky, 2012: 13). Una declaración escrita emitida por la asamblea de Nueva York y citada por Manuel Castells da fe de este empoderamiento del individuo, de esta pulsión por injertarse de nuevo en la narración histórica como ente protagónico:

El movimiento no necesita reivindicar nada porque es un proceso de afirmación. Este movimiento tiene el poder de realizar el cambio. No necesita pedirlo. OWS [Ocuppy Wall Street] no exige. Sencillamente afirmamos nuestro poder para conseguir lo que deseamos. Cuantos más nos unamos a la causa, más poder tendremos. No hay que exigir que otros te solucionen los problemas. Imponte (Castells, 2012: 186). 
Eso mismo hace The Yes Men, un dúo de activistas que se valen de la suplantación como medio para que ocurra lo que debería ocurrir. El Manual de guerrilla de la comunicación define su práctica como "La invención de hechos falsos para crear acontecimientos verdaderos" (grupo autónomo a.f.r.i.k.a., Blisset y Brünzels, 2000: 59). Valiéndose del fake, es decir, del acontecimiento falsario, inventan un acontecimiento con el que pretenden hacer que el mercado diga lo que realmente piensa. Todo queda más claro si atendemos a una de sus acciones: hacer pasar a uno de ellos por representante autorizado de la empresa Dow Chemicals, causante de la conocida como catástrofe de Bhopal (India) que en 1984 mató a miles de personas, quedando afectadas más de 600.000 por la enorme fuga de gases tóxicos. Apareció en la BBC con un comunicado que conmocionó a los medios: Dow iba a indemnizar a las víctimas de la catástrofe. Minutos después, se descubrió la farsa y Dow se desligó de las falsas declaraciones. Pero aquí comienza la verdadera repercusión: la multinacional ha tenido que defender públicamente su decisión de no indemnizar a las víctimas. The Yes Men han conseguido que Dow haga explícita su avaricia y acabe narrando su propia miseria moral:

El fake despliega su eficacia en el transcurso del proceso que sigue a su descubrimiento, en la cadena de desmentidos auténticos (...). El fake posee en cierto modo un efecto esclarecedor-emancipador: demuestra que todo podría ser también muy diferente, que las estructuras del habla y del poder, tal y como se le presentan al ser humano, ni son concluyentes ni naturales. En los procesos de comunicación, el fake hace vislumbrar aquel perturbador y potencialmente resistente "otro" de lo existente, que el discurso dominante condena al silencio a todos los niveles, sin conseguir nunca hacerlo desaparecer. El fake se basa, pues, en la interferencia o subversión momentánea de aquello que Foucault llama "el orden del discurso" y que identifica como elemento esencial del ejercicio de poder. (...) El fake hace que las ocultas estructuras discursivas del poder queden de repente al descubierto" (grupo autónomo a.f.r.i.k.a., Blisset y Brünzels, 2000: $67)$.

Injertarse en la Historia significa reapropiarse del papel actante y protagónico, de la soberanía que reinscribe al sujeto pensante en el devenir histórico que debería obrar en su poder de forma legítima. Las redes sociales hacen explícita esta reclamación y la universalizan. Una multitud de singularidades intuye tras el sistema representativo de las actuales democracias la desposesión de un poder de decisión que le pertenece y al que ya no está dispuesto a renunciar.

\section{Recuperar la propia piel}

El eslogan más famoso de Occupy Wall Street es "somos 99\%". Si tu saldo no es de millones de dólares, no lo dudes: eres uno de los nuestros. Con este mecanismo de 
inclusión, desde el anonimato, cualquier persona se siente identificada con la protesta. Todos somos Occupy Wall Street. Aquí no hay líderes, aquí cabemos todos. 99\% es una marca, un logo, un estilo de vida: el estilo de vida de los que sufren la crisis. La revolución no tiene rostro, porque la componen miles de caras sin nombre.

Tampoco tienen rostro más al sur, en la selva Lacandona de México, los miembros del Ejército Zapatista de Liberación Nacional, quienes cubren sus rostros con pasamontañas. Mucho ha llovido desde el día 1 de enero de 1994 en que se alzan en armas contra el Estado. Desde entonces, han colgado su arma al hombro, casi de forma simbólica, y han reconducido su lucha por los caminos de la literatura y el humor. Sus modos de enunciarse parecen renunciar a los antiguos patrones de la lucha armada ${ }^{8}$. El Subcomandante Marcos es la voz más mediática y reconocida del movimiento. Cuentista y guerrillero. Un verdadero hombre del Renacimiento. Con sus textos, el Sup ha ido elaborando un ideario lleno de metáforas y alegorías que parecen alejarlo del camino de las grandes utopías:

No queremos tomar el palacio presidencial (...). No queremos instaurar un igualitarismo radical que, a fin de cuentas, oculta una diferenciación entre la élite política minoritaria -de izquierdas o de derechas- y la mayoría empobrecida de la sociedad (...). No queremos el poder, ni tan sólo convertirnos en un partido político. Ya hay suficientes (Ramonet, 2001: 52).

Su lucha es la resistencia a desaparecer, su restauración como personas, como sujetos capaces de decisión. Su misión es no seguir siendo obviados, dejar de ser invisibles para el mundo. Resulta irónico, y en esto vemos como el EZLN se mueve como pez en el agua en esta guerra por reconquistar lo simbólico del lenguaje, que el medio para hacerse visibles sea ocultando su cara, borrando sus individualidades y adoptando un rostro neutro, un logo, una máscara inclusiva en la que todos ven delineadas sus facciones. El pasamontañas no es nadie, no es nada en sí mismo más que el estilo de vida de los que quieren ser vistos. Asimismo, radican su lucha en la ocupación de ese otro espacio no pisable, el espacio virtual donde enraíza el nuevo entramado social. Con un mensaje sugerente, a medio camino entre la poesía y la narración, los cuentos del Sup son leídos en todos los rincones del mundo y, de este modo, en todos los rincones del mundo hay un zapatista en potencia.

\footnotetext{
${ }^{8}$ Es, como mínimo, curioso el caso de las FARC, quienes hacen pública su aceptación de diálogo con el gobierno mediante un vídeo colgado en la red. En él vemos a los guerrilleros cantando una rap en el que expresan su desacuerdo con el presidente Santos y su agradecimiento a los países que intervinieron en pro del diálogo. Sorprende la repentina transmutación del estatuto del guerrillero latinoamericano, que obviamente cuenta con el precedente de Marcos y la literaturización de la lucha.
} 
Debemos considerar esta máscara negadora del propio rostro a la luz de la reflexión de Luther Blisset y Sonja Brünzels acerca de la idea de los nombres múltiples. Ocultando un rostro particular se intuyen en él todos los rostros posibles. Su negación, es decir, su logo, esconde la posibilidad de todas las individualidades:

Uno de los méritos más geniales de la guerrilla zapatista consistió en convertir el nombre de (...) Marcos en un nombre colectivo. Con esta práctica no sólo seguían con su intención de deconstruir el mito del líder de la revolución (...) sino que a la vez crearon una forma nueva de mito colectivo: la persona del guerrillero real no tiene una historia clara e identificable (grupo autónomo a.fr.i.k.a., Blisset y Brünzels, 2000: 40),

de tal forma que todos somos ese guerrillero, formamos parte del mito. Como dice el propio Subcomandante:

Marcos es gay en San Francisco, negro en Sudáfrica, asiático en Europa, chicano en San Isidro, anarquista en España, palestino en Israel, indígena en las calles de San Cristóbal, (...) judío en Alemania nazi, (...), feminista en los partidos políticos, comunista en la posguerra fría, preso en Cintalapa, pacifista en Bosnia, mapuche en los Andes, (...) artista sin galería ni portafolios, ama de casa un sábado por la noche en cualquier colonia de cualquier ciudad de cualquier México, (...) machista en el movimiento feminista, mujer sola en el metro a las 10 p.m., jubilado en plantón en el Zócalo, campesino sin tierra, editor marginal, obrero desempleado, médico sin plaza, estudiante inconforme, disidente en el neoliberalismo, escritor sin libros ni lectores, y, es seguro, zapatista en el Sureste mexicano. En fin, Marcos es un ser humano cualquiera en este mundo. (...)Todos los intolerados buscando una palabra, su palabra, lo que devuelva la mayoría a los eternos fragmentados, nosotros. Todo lo que incomoda al poder y a las buenas conciencias, eso es Marcos (Subcomandante Marcos, 2003: 245).

David Franco Monthiel, refiriéndose al nombre colectivo Luther Blisset que numerosos activistas usan en todo el mundo, comenta que fue una forma de "desembarazarse de una vez por todas del concepto de individuo (...).Todos podemos ser Luther Blissett. El ataque a los conceptos burgueses de sujeto se radica en transformar de repente, (...) a individuos reales en personas colectivas" (Franco

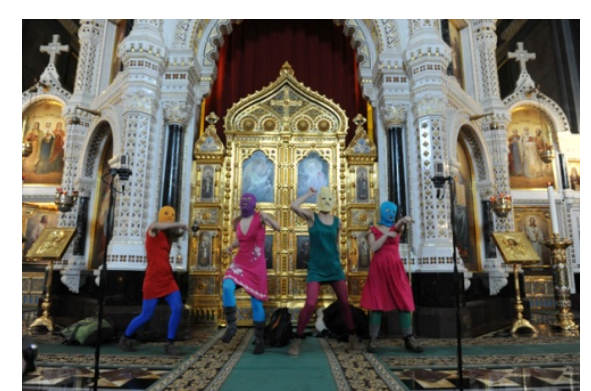
Monthiel, 2003). Así, el contra-poder asume y supera la crisis del sujeto moderno, esa individualización que desmembró el entramado social y consigue que tal inconveniente juegue a su favor. 
Al otro lado del globo, las rusas Pussy Riot también ocultan sus caras con balaclavas de colores. Hasta que el gobierno no las ha desenmascarado, Pussy Riot no tenía rostro. Su anonimato era su logo, su imagen de marca. Muestra de ello es que miles de personas en todo el globo reivindican la libertad de las componentes de esta banda de punk feminista, detenidas y recluidas por cantar uno de sus temas contra Putin en la Catedral de Moscú, con un gesto particular: hacerse fotos cubriendo sus caras con improvisados balaclavas de colores y hacerlas circular en la red. Como ellas mismas reconocen en una entrevista: "The principle of our image is that no personality should stand out in the show, and no identity of a particular girl can be recognized. It's close to the ideas of Guerilla Girls, who had nicknames and masks"9.

Un efecto análogo busca la máscara de Guy Fawkes, protagonista de la película $V$ de Vendetta, que Anonymous ha tomado como logo. Gente sin nombre que oculta su rostro tras una idéntica careta para formar parte de una reivindicación global, una máscara que oculta a todos por igual para que nadie vuelva a sentirse invisible. Y podríamos citar innumerables ejemplos en los que vemos reivindicada esa demanda de visibilización, como es el caso de Los Reflectantes ${ }^{10}$, quienes llevan a cabo sus intervenciones forrados en trajes que reflejan la luz solar: "Antes éramos invisibles. Ahora somos reflectantes". Además de exigir visibilidad, tratan de reflejar la verdadera cara del sistema; de algún modo son el espejo de la sociedad que los obvia. Sin embargo, por su especial significación, vamos a centrar nuestra atención en las bolivianas Mujeres Creando, un movimiento social anarcofeminista:

Locas, agitadoras, rebeldes, desobedientes, subversivas, brujas, callejeras, grafiteras, anarquistas, feministas. Lesbianas y heterosexuales; casadas y solteras; estudiantes y oficinistas; indias, chotas, cholas, birlochas y señoritas; viejas y jóvenes; blancas y morenas, somos un tejido de solidaridades; de identidades, de compromisos, somos mujeres, Mujeres Creando (Álvarez, 2005: 35).

\footnotetext{
${ }^{9}$ Guerrilla girls era un colectivo feminista de artistas que, nacido en el Nueva York de los años ochenta, se dedicaba a señalar las desigualdades en el mundo del arte. Reivindicaban una mayor presencia de mujeres en el arte, más allá de ser inspiradoras de retratos que cuelgan en los museos. Ocultando su rostro en máscaras de gorilas, evitaban ser reconocidas, así que nunca se supo muy bien cuántas personas conformaban el grupo.

${ }^{10}$ Los reflectantes nacen en el marco del Encuentro Internacional de Activismo Creativo Cómo acabar con el mal, que tuvo lugar el pasado año en Barcelona. En el dossier del evento, el Colectivo Enmedio, organizador del encuentro, declara sus intenciones: "buscamos dotarnos de una serie de herramientas creativas aplicables a la acción social, tanto en la calle como en la Red. Nuestro objetivo es inventar nuevas maneras de actuar en el contexto de la crisis, nuevos modos de intervención basados en prácticas artísticas. Acciones que se escapen de la lógica violencia-no violencia, modelos originales de protesta y de acción directa capaces de sortear tanto la represión policial como la manipulación mediática".
} 
Han causado gran revuelo por sus grafiteadas, algo a medio camino entre el grafiti y la pintada, mediante las que reivindican un papel protagonista para las mujeres, incluso aquellas que ocupan los márgenes de la sociedad: “indias, putas y lesbianas, juntas, revueltas y hermanadas", organizadas con autonomía respecto a los partidos, a las organizaciones no gubernamentales, al gobierno, a la Iglesia... Se declaran abiertamente ácratas, ajenas a cualquier discurso partidista que trate de contenerlas. Mujeres Creando es una suerte de marca donde todas somos posibles; un logo que habla con la voz de todas la mujeres. Mujeres Creando es un nombre colectivo: cuando cualquier persona de cualquier país pinta una grafiteada y la firma como Mujeres Creando, es ya Mujeres Creando y forma parte de ellas anónimamente. Es muy significativa, al respecto, la caligrafía que comparten e imitan en cada una de sus frases, un trazo en minúsculas con letras redondeadas y ligadas entre sí: su logo, su imagen, su estilo de vida reconocible por todos.

Parten de la idea de que cualquier institución lleva en su germen los modos de dominación masculina: "No hay nada más parecido a un machista de derechas que un machista de izquierdas y un indígena: la misma pistola", leemos en los muros de La Paz. Como afirma María Galindo, se valen del

uso de la palabra como uno de los elementos políticos fundamentales para replantearnos qué entendemos por política, cómo nos vamos a comunicar con la sociedad, cómo vamos a expresar nuestros sueños de cambio, en un momento en que el lenguaje de los sindicatos, de las izquierdas estaba desgastado, era repetitivo, yo diría que era un diálogo de sordos, un lenguaje muy militarista, heroicista, e incluso muy victimista, y también un lenguaje absolutamente de machos.

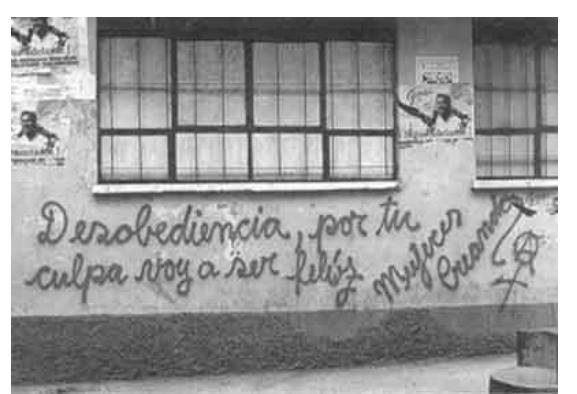

Habrá, entonces, que reapropiarse de los códigos y reinventarlos, parodiar el lenguaje del adversario y hacer que se revuelva contra el poder falocéntrico. Llama la atención que los eslóganes de Mujeres Creando incidan especialmente en lo cotidiano como centro de la revuelta: "Desobediencia: por tu culpa voy a ser feliz", "Nuestra venganza es ser felices", "Mujer que se organiza no plancha más camisas". No se hacen eco de consignas políticas, no instan a grandes revoluciones. Son frases improvisadas que instan a pequeñas revoluciones en el plano de lo privado, en esos rituales domésticos que deben ser el primer objeto de cambio. Tomando lo personal como político conforman un ideario que toma la calle y se convierte en intervenciones públicas, verdaderos acontecimientos en el sentido revolucionario de la palabra: colocar un condón gigante al Obelisco de La Paz como símbolo fálico del poder político, pintar y medir penes 
en plena calle ${ }^{11}$, una misa cuyo oficiante es una mujer, desfiles de moda con blancos vestidos de novia manchados de sangre... Pocos movimientos meten tanto el dedo en la yaga y señalan con tal precisión el origen del malestar. Lo grotesco se vuelve catártico en sus performances. Retuercen los significantes con los que el macho enuncia su poder; mujeres creando el lenguaje de la subversión que las define.

Son incontables los ejemplos de movimientos antagonistas que podríamos recopilar, pero no era esta la naturaleza del presente artículo. Simplemente, se pretende señalar el carácter urgente de una revisión de las antiguas nociones de activismo para, con ello, arrojar luz sobre las múltiples intervenciones sociales que apuntan a redefinir el poder, a desenmascararlo.

Debemos retomar, a modo de conclusión, el concepto de reapropiación con el que abríamos este trabajo y que lo vertebra. Si el lenguaje se ha convertido en pasto del mercantilismo, los movimientos sociales interfieren en los canales comunicativos, recuperando la capacidad de decir y de contradecir. Frente a la usurpación del espacio público, los grupos antagonistas proyectan nuevos modos de ocupar las calles, de embellecerlas y de asumirlas como el lugar de la convivencia que debería ser. Si el neoliberalismo predecía el fin de la Historia detenida en un eterno triunfo de la dictadura del dinero, una multitud la vuelve a poner en marcha reivindicando una verdadera representatividad y la soberanía que legítimamente debería residir en sus manos. Si los gobiernos han ninguneado la voz de los excluidos y les han negado la dignidad, los activismos sociales la reclaman como algo propio, genuino, connatural y esencial en el sujeto político que la multitud representa como potencia. La revolución ya no es una guerra: es una forma creativa de guerrilla por la propia visibilización, una celebración de la vida; la toma de posesión de algo que siempre debió ser nuestro, la reapropiación de los espacios y medios que nos definen como sujetos dentro de la Historia. En definitva, recuperarse a sí mismos. Como afirman Mujeres Creando en sus grafiteadas, "nuestra venganza será ser felices".

11 "Un pene, cualquier pene, es siempre una miniatura", reivindica una de sus grafiteadas. 


\section{Bibliografía citada}

Álvarez, Helen (2005). "Utopía: cabalgadura que nos hace gigantas en miniatura”. Mujeres Creando La Virgen de los Deseos. La Paz: Tinta y Limón.

Baudrillard, Jean (2005). Cultura y simulacro. Barcelona: Kairós.

Bauman, Zygmunt (2001). La sociedad individualizada. Madrid: Cátedra.

Castells, Manuel (2012). Redes de indignación y esperanza. Madrid: Alianza.

Chomsky, Noam (2012). Ocupar Wall Street. Indignados en el epicentro del capitalismo mundial. Barcelona: Urano.

Delgado, Manuel (2007). Sociedades movedizas. Pasos hacia una antropología de las calles. Barcelona: Anagrama.

Desayuno con viandantes. "Dossier". Desayunoconviandantes.org. (2012).

Eco, Umberto (1999). La estrategia de la ilusión. Barcelona: Lumen.

Fernández de Rota, Antón. "Hacia una redefinición posmoderna de la revolución política. Acontecimiento, poder constituyente y disutopía". Nómadas. Revista Crítica de Ciencias Sociales y Jurídicas 19 (2008): 73-92.

Franco Monthiel, David. "Wu Ming, esta revolución no tiene rostro". Rebelion.org, (2003):

Fukuyama, Francis (1992). El fin de la historia y el último hombre. Barcelona: Planeta.

Grupo autónomo a.f.r.i.k.a.; Blisset, Luther y Brünzels, Sonja (2000). Manual de guerrilla de la comunicación. Barcelona: Virus.

Hardt, Michael y Negri, Antonio (2002). Imperio. Barcelona: Paidós.

Klein, Naomi (2001). No logo. El poder de las marcas. Barcelona: Paidós.

Lipovetsky, Gilles (1990). El imperio de lo efímero. La moda y su destino en las sociedades modernas. Barcelona: Anagrama.

Lipovetsky, Gilles (2005). La era del vacío. De la era de lo sagrado al tiempo de las marcas. Barcelona: Anagrama.

Lyotard, Jean-François (1998). La condición postmoderna. Madrid: Cátedra.

Pititako. "Entrevista a María Galindo y Florentina Alegre". Jakina 6 (2004).

Ramonet, Ignacio (2001). Marcos. La dignidad rebelde. Valencia: Cybermonde.

Subcomandante Marcos (1994). "Comunicado del 28 de mayo de 1994". EZLN Documentos y comunicados 1. México D.F.: Ediciones Era.

Taibo, Carlos (2009). En defensa del decrecimiento. Sobre capitalismo, crisis y barbarie. Madrid: Catarata. 
Injertarse en la Historia.

Estrategias de reapropiación en el activismo global

Virno, Paolo (2003). Gramática de la multitud. Madrid: Traficantes de sueños. 